Published as:

Jackson, J. (2005). My dance and the ideal body: looking at ballet practice from the inside out, Research in Dance Education, 6(1-2), 25-40. Available online at:

http://dx.doi.org/10.1080/14617890500373089

\title{
My dance and the ideal body: looking at ballet practice from the inside out
}

Jennifer Jackson, University of Surrey, Guildford, UK

\begin{abstract}
This paper argues for a change of thinking about the 'ideal body' in relation to ballet as a dance form and how it is studied. It distinguishes between spectator and practitioner perspectives on ballet, and draws on the practice of established dance artists and that of the author to write about the firstperson experience-from the inside out. Using a balletic concept, en dehors/en dedans, as a metaphor, the discussion moves from looking at the outside product of the ballet inwards to look at the inside processes or practice. The impact of the spectator perspective on the characterization of practice is considered, raising questions about the construction of binaries such as free/rule bound and the perception of the body and form as fixed. A case is made for ballet study as a somatic practice, and how engaging the first-person experience and perspective on the body allows the individual dancer to develop as both artist and technician.
\end{abstract}

I sat on an audition panel in July 2004 with a colleague whose career in the Royal Ballet had overlapped with mine. We were selecting dancers who showed potential for pre-vocational training in ballet and, prior to the auditions, we shared our concerns about the state of the art, the emphasis on bodily potential for training and athletic over artistic achievement, and a cultural context where the 'ideal body' as image is a powerful influence. We both reflected on how-in our experience of training and then dancing professionally - the inner and individual spark of 'wanting' to dance that we identified as a vital component of the potential we were assessing had been under-explored. Acquiring the skills for dancing takes years of study that, arguably, never ends; the dancer who 'lives' on stage resolves her 'wanting' as expressive motion that is both personal and connected to the tradition. How, then, is the specific potential of that 'wanting' to dance engaged in educating the ballet artist of today?

In this paper, I argue for a change of thinking about the 'ideal body' in relation to ballet as a dance form and how it is studied. I draw on my own experience and begin by building a rationale for writing from the first-person perspective about practice. In 
the paper, I use a balletic concept, en dehors/en dedans, as a metaphor to provide a structure for the discussion, and move from looking at the outside product of the ballet inwards to look at the inside processes or practice. I evaluate writing about ballet from spectator and practitioner perspectives and consider the impact of the en dehors (outside) perspective on the characterization of practice, problematizing the construction of binaries such as free/rule bound and the perception of the body and form as fixed. I reference ideas from somatic studies to suggest that the outside perspective on ballet is categorically different from the inside perspective and, thus, on the nature of what is perceived. I reflect on how in the dialogue between ballet and somatic study there may be insights into how the individual may use her ballet education to develop as both artist and technician. I emphasize another perspective on ballet practice-from the inside out.

I predominantly look to and reference the testimonies of practitioners as evidence in order to explore knowledge embedded in practice itself (the epistemology of practice). While I acknowledge the resonance of the debates raised in this paper with phenomenological philosophy and behavioural psychology, I do not engage discursively with these texts. I attempt to write simply from my expertise in dance practice.

\section{Writing from the first person}

For the dancer, a frustration of the writing project is this: I cannot simultaneously represent all the ideas and processes that are revealed in one moment of dancing. A challenge is in communicating the experience from the perspective of practical knowledge of the 'how' and 'why' of those processes and ideas.

The complexities in accounting for live dance and its methodologies reach across settings and practices. At a Ballet Independents' Group Discussion Forum about ballet as both vocational and academic study in 2002, ${ }^{1}$ Michael Irwin, Professor of English at Kent University and academic adviser to the first postgraduate students at London Contemporary Dance School, pondered the problems for academic study posed by the dance text that he considers unrepresentative of the 'thing itself' (Irwin, 2002). Educational philosopher Chris Challis (2002) posited synergies in the way all students engage intellectual rigour in dancing. Studio work is implicitly reflective, but where and how are the new knowledge and skills of practice articulated? According to dance artist Kirsty Alexander, dance lacks a methodology for evaluating the firstperson kinaesthetic experience, and within academic scholarship dance is 'intellectually mediated via external (third person) received knowledge' (2003, p. 19).

Reflecting on the 'curiosity of writing' in academia Susan Melrose says:

our writing will always be 'about performance'. The preposition 'about performance' signals not simply expert-spectator positioning with regard to others' performance practices, but equally the synoptic power of language. (Melrose, 2003, p. 4; emphasis in original) 
Melrose suggests that the writer brings 'textualist paradigms to the event and our perceptions of it', adding that while this strategy serves the expert spectator well, it is 'no friend at all of expert practices or practitioners' (2003, p. 4). Melrose's precise observations indicate the nature and different outcomes of the third-person/writer and first-person/practitioner viewpoint on practice. Simple questions-from where, how and at what do I look?-impact on the account of dance offered. Melrose suggests that "expert spectating as writing-productive controls "performance" after its event' (2003, p. 4), even if the writer chooses language that acknowledges the fluid nature of performance. I concur: in the activity of writing the spectator fixes the (dance) performance; on the other hand, in the activity of dancing the practitioner releases the (dance) performance.

Does a polarity of positions suggest polarity of the domain or subject under study? My own teaching practice straddles distinct contexts, with practical ballet technique at the University of Surrey, Guildford, and choreography at the Royal Ballet School, London. Although the format of the technique and choreography classes is different, I draw on the same principles from my subject (ballet) in both. For example, en dehors/ en dedans is employed as a tool for exploring the internal organization and discovering expressive dimensions of movement material. The work is about exploring the relationship of the dancer with the outer (public or given) dance and with her inner 'wanting' to dance.

What are the implications of third-person and first-person positioning on the ballet 'text' and the elements of practice? How might looking from the inside construct an alternative view of ballet to those offered by experts, such as Susan Leigh Foster and Roger Copeland, who are positioned outside of practice? For the purpose of clarity, from this point I refer to 'practice' specifically as the dancer's work in acquiring technique in class and learning to dance.

\section{Outside perspectives on the form}

In ballet, the terms en dehors and en dedans describe movement and also suggest position. Movement outwards (en dehors) forms an open position, ecarté, and the movement inwards (en dedans) forms a closed position, effacé. They point to a placeinside or outside. Thus they evoke something of the interplay in dancing of movement and shape-between inside and outside, between the body and its location in space and in relation to practice-and can imply perspective.

A common view of en dehors is its reference to the dancer's 'turnout'-her physical ability to 'open' the body and rotate the legs in the hip sockets. It can also refer to her temperamental openness - the capacity for learning and ability to communicate. ${ }^{2}$ Adrian Stokes (1983, p. 244) considered turning-out as the 'essence of ballet', and in its physical form, he and Selma Jean Cohen, among others, have identified the quality of outwardness. Cohen (1982, p. 119) describes the 'extroversion' of the 'entire person', who is open but not vulnerable, to other bodies and the surrounding space. 
The turnout functions to facilitate ease and a wide range of movement in both legs and arms. In Lincoln Kirstein's (1983) consideration of the distinctions between modern dance and ballet, he states that 'the root of ballet-training in the five academic foot-positions ... determine[s] the greatest frontal legibility and launch of the upper body as silhouette framed in a proscenium' (1983, p. 240). It is predominantly 'fast' and 'kinetic'. In modern dance, Kirstein says focus is 'on and in central somatic areas of the body, rather than extension of peripheries' (1983, p. 241). Roger Copeland discusses the 'sensibilities' classical ballet and post-modern dance share as characterized by the 'objective temperament', which engenders 'impersonality'-the ability to 'stand outside oneself. He says that for the ballet choreographer, 'impersonality and objectivity come "ready-made"-complements of the movement vocabulary itself, that exists previous to the individual dancer or choreographer' (1986, p. 8).

Writing from her 'lived' experience in Dance and the lived body, Sondra Horton Fraleigh (1987) draws on phenomenology and existentialism. She perceives the different content of modern dance and ballet as emanating from individual freedom and contrasts the modern dancer's 'courage to be oneself' with 'the security of rule that grounds classical dance forms':

Permanency, through reproduction of a given form or a well-established movement model, is not as important to modern dance as creativity. In contrast, the ballet concentrates on achieving idealised movement forms ... It has an established movement vocabulary, embodying balletic ideals subject to stylistic interpretation. (Fraleigh, 1987, p. xxxiv)

On a spectrum from inside to outside, these characterisations reflect a perception of ballet as 'out there'-display, confident, loud, hard and getting 'harder faster longer higher', as Foster (1995, p. 109) has provocatively suggested.

For these writers, who comment as expert-spectators with great knowledge and sophistication about ballet as product, associations are indeed with notions of the ideal, abstract, objective, public, technical—and fixed. For the practitioner, product and process are interrelated and indivisible; so the emphasis on periphery rather than 'soma', and the idea of ballet as ready-made rather than the outcome of a courageous and creative process, raise concerns about its practice and how it is represented.

In her writing about creative strategies employed within practice, Knorr-Cetina makes the 'simple' point that 'a stable name is not an expression or indication of thinghood' (2001, p. 184). Until realized by executants, the ballet vocabulary is a code or sign for movement ideas or concepts and of itself does not embody balletic 'ideals'. Furthermore, its 'established' nature can be misleading. Over-familiarity with existing images of ballet can discourage creativity and breed habitual practiceobedient but mindless repetition.

The very objective knowledge, codified vocabulary and legibility that make ballet powerful can distance it from the activity of dancing. When I asked my current Royal Ballet School students what they thought ballet was, the first reply was: 'a collaboration of steps', a smart, objective idea. What does this remark suggest about the connectedness of that individual's experience of dancing ballet with his/her dancing self? Where is the movement en dedans? And at what price its invisibility? 
Copeland's (1986) notion of the 'ready-made' evokes a production line rather than the complexities of choreographing or learning to dance ballet. Stokes's (1983) idea of 'outwardness' as the essence of ballet, embracing the physical and temperamental openness already identified, is more fluid than Copeland's objectivity as impersonality. He links objective and form not with 'ready-made' vocabulary, but to the human being, positing that 'all art is conversion of inner state to outward objective form' (1983, p. 247). This sounds like a messy, expressionist goal, from which Copeland would prefer to distance ballet. Copeland's writing stresses arrested form, implying a fixed position. Stokes's focus on a concept or property of ballet-i.e. turning-outsuggests movement outwards.

In teaching students ballet, learning to dance from the inside out is vitally important. If dancers merely reflect existing images, the kind of dance that Tony Geeves (1993, p. 12) describes as an 'objet d'art', the ballet is reproduction, both for spectators and participants. Locked in 'fixed' notions of ideal form without reference to its current cultural context, it runs counter to Diaghilev's notion of 'classicism' as means not end. And 'out there' is the dancer always struggling to achieve an 'ideal body' without reference to her own body, which may already be ideal?

\section{My self, my ideal body, my own dance}

The provenance and nature of third-person and first-person perspectives on ballet performance and practice raise parallel questions about perspectives on the body. Since 1996, I have studied ballet with Roger Tully, who, now aged 77, runs a private studio in London that attracts international professional dancers and vocational students. His own studies with Kathleen Crofton, Stanislaz Idzikowsky and Marie Rambert connect through an oral tradition to Enrico Cecchetti. Core to Tully's teaching practice is his concept of the dancer's own dance and her body in relation to principles of movement. He suggests that: 'you have the ideal body for your own dance-and your dance refines your ideal body. ${ }^{3}$

Before I began studying with Tully, I was introduced to Feldenkrais technique at a weekend workshop for actors, led by Jos Houben of Theatre de Complicité. He employed Feldenkrais to educate economy and grace (very quickly) in movement, connecting the imagination with one's awareness of the 'felt/internal' function that I linked to breath. This experience laid the ground for my receptivity to Tully's approach to teaching ballet, which has transformed my practice and sown the seeds of my interest in how ballet is a 'somatic' study.

'Somatics is the field which studies the soma: namely the body as perceived from within by first-person perception' (Hanna, 1995, p. 341). The notion of ballet as a somatic study allows me to consider aspects of practice from the first-person perspective-my/self. Behavioural psychologist Erving Polster (1995) identifies the individual as a 'collection of selves'; from the inside, I see my/self not as a dancing 'body', but as a human being, one of whose 'selves' is a dancing self. 
I think of my body as a 'lived body', as in Fraleigh's concept that 'attempts to cut beneath the subject/object split, recognising a dialectical and lived dualism but not a dualism of body-soul or body-mind'; she describes dance as 'the art that intentionally isolates and reveals the aesthetic qualities of the human body-of-action and its vital life' (Fraleigh, 1987, p. xiii). I see the vital life as connected with the sense of self that I feel to be individual, and my 'wanting' to dance. I see my 'own dance' as the particular collaboration of my 'wanting' to dance and the materials and knowledge I employ in the process of shaping the form of my dance.

Tully's concept is rich in ideas, imagery and movement. He uses a diagram of a spiral to illustrate the process of the forming of the dance and refining of the body. Outwards (en dehors) from your own (inner) dance through the medium of the body and mind to the (outer) dance and inwards (en dedans) from the dance connecting your body/mind with your own dance. Thus the outward (expanding) spiral enables the inward flow of information about the form and the inward (contracting) spiral closes the outward expression and form of the dance. Just as an in-breath opens and expands the body and mind, so the out-breath releases the shape of the movement and closes and relaxes the body and mind. Taking a breath is the first independent movement that I make as a human being. At a fundamental physical level, and on an imaginative metaphysical level, this process connects my own dance with what I feel it is to be myself.

\section{Somatic practices in dance education}

Somatic practices make clear distinctions between first-person and third-person perspectives and, thus, implicitly 'reject the Cartesian notion of a mind-body duality' (Alexander, 2003, p. 19). Further, a somatics approach emphasizes that looking from the first-person perspective affects the nature of what is perceived:

When a human being is observed from the outside-i.e. from a third-person viewpointthe phenomenon of the human body is perceived. But, when this same human being is observed from the first-person viewpoint of his own proprioceptive senses, a categorically different phenomenon is perceived: the human soma. (Hanna, 1995, p. 341; emphasis added)

Because they are perceived as developing awareness of body/mind connections, somatic practices are part of the curriculum in many vocational and academic institutions. In her research investigating somatic study in dance education, Sara Reed finds that many of its principles are 'inherent within dance technique' (2002, p. 3); Fortin contends that cross-fertilization between somatic and dance practices has promoted creative practice in dance (2003, p. 3 ).

As movement practices somatics and ballet would appear to lie at opposite ends of the inner/outer, self/other and private/public spectrum. In her keynote address at the 'New Connectivity' Conference, at the Laban Centre, London, Fortin (2003) used the idea of 'dancing on the Möbius band' to illustrate how apparently contradictory modes of operation are reconcilable within the continuity of a band that spirals. She demonstrated how a twist in the band allows a fluid exchange of self to other, inner to outer. Rooted in ballet practice is a similar concept, en dedans/en dehors, inwards and outwards. I pondered on the similarity of flow between object and subject; intake 
of information and outward expression/form of dance; reflection and concrete shaping; ideas and action; and body and mind, in my own recent experience of studying ballet with Tully. Key to my argument, in this paper, is the relationship that is suggested by somatics of the dancer with her own body and the importance of looking from the inside of one's self at one's own experience of practice. I contend that looking only from and at the outside leads to the absence of self and an unhelpful objectification of the body, so that it is no longer the dancer's own. ${ }^{4}$

Reed cites Fortin et al's (2002) work as highlighting how a specific (somatic) awareness is 'fundamental to the real assimilation of movement principles' (2002, p. 3). However, somatic practices—body/mind disciplines, body therapies, somatic therapy, movement awareness (see Reed, 2002, p. 2) - are orientated not towards producing performance in a particular movement 'style', but towards a general optimum functioning of the body/mind (that also promotes health). Therefore they complement technique training but do not engage with information that will develop the dancer's knowledge and the dance instrument of a specific form. Ballet study might be characterized as educating the dancer's somatic awareness to assimilate specific movement principles. For this information the dancer must look outside herself to the principles, to the tradition and to dance as a discipline.

\section{Perspectives on practice}

Discipline implies a framework for study and a body of knowledge, both the concepts and principles of the particular area and its ordering or training practices-that is, ways of engaging with the knowledge base (Adshead-Lansdale, 1981, p. 8). As has been suggested, over-familiarity with terminology encourages thoughtless and habitual practice. Lack of reflection infiltrates both inside and outside perspectives on the most fundamental of activities for the dancer, the daily class. For example, the easy association of discipline with training and 'drilling' rather than education breeds a narrow conception of what is involved in learning ballet technique.

Ninette de Valois's series of groundbreaking courses in the 1950s with the Royal Academy of Dancing on the 'The constructive teaching of ballet' are the meat behind Joan Lawson's (1960) study of classical ballet style and technique. Lawson, whose practical ballet teaching at the Royal Ballet School inspired many of my colleagues in the 1960s and 1970s, defines the plié, tendu, relevé, etc. as the 'physical qualities' of classical dance. She sees a correlation between the dancer's discipline and her freedom of movement in a specific style: 'The greater the discipline maintained during the daily practice of classroom exercises the greater will be the dancer's freedom to express themselves in classical or any other form of dance' (1960, p. 25). Reasons she cites for this freedom emphasize not the effectiveness of an imposed training system, but the dancer's agency: her awareness of body parts, their interrelationship and function in movement, the dancer's ability to coordinate and make choices and her understanding of principles and qualities of movement. The dancer's (self) discipline enables her effective engagement with the concepts and procedures of ballet as a discipline. 
Peter Wright and Barbara Fewster (Crow \& Jackson, 2001a, p. 16) have pointed to the impact on how students learn ballet in the shift from imposing to nurturing discipline from within. ${ }^{5}$ The significance of the movement from outer to inner shifts agency towards the dancer herself in the ballet class (and alters the balance of the elements that form her dance). Writing about a confusion and loss of confidence she perceives among ballet educators, Lynn Seymour (2000, p. 313) draws attention to her early lessons in the 1950s and the value placed on 'doing one's personal best': 'it was the integrity of your work, your tenacity and determination that counted, not being the best in class.' In 'Dancing bodies', in which Susan Leigh Foster examines the nature of training in five dance techniques, she says of today's ballet class that 'competition although quiet, is fierce-in part because the standards for perfection are so clearly defined’ (2003, p. 243).

Seymour's reference to tenacity and determination is perhaps what also drives the competition that characterizes Foster's class. What Seymour sees as a healthy drive towards 'personal best', Foster perceives as differently orientated towards the pursuit of already-defined standards of perfection, outside of the person dancing. Foster's article raises several important issues. She paints a picture of dance training as closed 'systemic programs of instruction' for bodies-'perceived, ideal, demonstrative, hired'-and involving habits, struggle and pain-'constructive, chronic, destructive' (2003, pp. 238, 240). Seymour 'prefers education to training', as a term, and her description of her learning experience speaks of the interplay of the imagination and sensing with concrete physical embodiment of ideas and concepts about space and music. She speaks of her teachers 'instilling joy', and of individuals who imparted 'knowledge ... that serves as a mainspring, informing our development and character, maintaining our ardour and enriching our lives' (2000, p. 313).

I choose these polarized examples to emphasize the different foci possible in learning to dance. Foster concentrates on 'drilling', which she says is 'necessary because the aim is nothing less than creating a body (2003, p. 239; emphasis in original), a finite object. Seymour stresses the development of the person who dances - a moving being.

\section{The ideal body}

The focus on the body, as against the person who dances, links standards of perfection to the instrument of the dance rather than the dancer or the dancing itself. But both my body as instrument and myself as dancer are integrated in the dancing experience and are inseparable in the dance.

The production in 'ballet environments' of tall, slim, identical bodies raises concerns about the ecology of the art form and the balance in the relationship between the raw materials of a body and the dancer herself in training (Crow \& Jackson, 1999, p. 40). In 2000, Krissy Keefer claimed that acceptance on to San Francisco Ballet's pre-vocational training programme was predicated only on body type (Crow \& Jackson, 2001b). ${ }^{6}$ A widely publicized case, it drew attention to society's preoccupation with body image and the specific body type that stands as a prerequisite for ballet training. The San Francisco Ballet School's published criteria on the body type of the ideal candidate prescribed a 'well-proportioned, slender body; 
a straight and supple spine, legs that are well turned out from the hip joint and correctly arched feet' (http://www.sfballet.org/school/index.php).

Integral to the health of the art form is that of its dancers and, according to Carl Rodgers (1977), 'trust in one's own organism is a prerequisite for the health of self' (quoted in Geeves, 1994, p. 9). Tully's conception that 'you have the ideal body for your own dance-and your dance refines your ideal body' questions prescriptive demands for one body type that pervade much of ballet practice. His approach requires a shift in thinking about the ideal body as integrated with the individual dancer's exploration of dancing. Beginning with the dancer's own dance brings the focus of activity to the process of learning to dance, to the study of dance as a subject as against the product of the body as object. Thus, I enter the studio, at any stage of my life, with my dance and not only with my body. I have the ideal body for my dance at that moment. This idea potentially frees the dancer from the limitations of a fixed idea of her ideal body-her body is always in the process of being formed. It liberates her to work with, not despite, her body and to look, listen, sense its responses and feel its reality as the carrier of functional information. As there is only one ideal body (hers), she is relieved of the 'wanting' for the ideal body.

In Foster's 'meat-and-bones' approach to writing about the dancer learning to dance, the body is dissected into 'bodies-of-ideas', which results in the creation of two bodies - a 'perceived and an ideal body' - both of which are comprised of the 'biological body' (2003, p. 235). Her characterization of training as instruction, where the 'body seems constantly to elude one's efforts to direct it' (2003, p. 237), renders the body remote from the self and blocks the relationship between the dancer's 'wanting' to dance and what she is dancing. Foster's position appears to uphold the idea of the Cartesian mind/body split, where the body 'functions as a machine to execute what the mind wills' (Fraleigh, 1987, p. 161):

The prevailing experience is one of loss, of failing to regulate a mirage-like substance. Even after attaining official membership in the profession, one never has the confidence in the body's reliability. (Foster, 2003, p. 237)

Such a perspective persists in wanting to pin down a permanent body. In doing so, it fails to apprehend the role of training in fitting the dancer with the expertise to begin professional life as a performer and denies the possibility of a nurturing, artistic practice as a process.

I support Matthew Hawkins's (1999) view that knowing one dance style in depth can equip a dancer with the skills to study another. Foster characterizes the "hired body' as one that has engaged with several different technical styles, and is thus able to re-produce movement as surface gloss, but to inhabit none of them deeply. She states that her descriptions of five different techniques derive from choreographers' and critics' writings, as well as her own experience in class. I question the depth and nature of this experience. Her writing about the creation of a body and the way the writing constructs the body/mind and self as separate entities suggests the third-person perspective, not the first-person experience; her conception of practice is thus categorically different from Hawkins's or Seymour's or mine, as experienced practitioners. 
Duerden and Fisher question Foster's notion of dancing as tied to aesthetic understanding in a particular technique; they point to the evolving nature of dance techniques, such as ballet, asking whether a 'dance technique can become crystallised and still live' (2002, p. 4). I also suggest that her account of a self in ballet that 'exists to facilitate the craftlike acquisition of skills; to serve the choreographer and, ultimately the tradition by ordering the body to practice and then perform ideals of movement' (Foster, 2003, p. 243) is devoid of artistic learning. It reduces both the agency and individuality of the dancer as a moving human being in her own process of learning. The locking of dance training or education as 'systems' of production sets up an imbalance between body and self and fails to see that it is the human being who must resolve the highly complex process of learning to dance, ultimately, in her own way, in her own dance.

\section{My dance}

How does the ballet dancer engage with her own dance in ballet practice? In the context of her paper, arguing for the education of dancers as artists, Gill Clarke, a modern dancer equally admired for her artistry and technical achievement, says:

I personally never thought I had a particular interest in science and yet, when I began to explore movement from the inside out, to think in the body, or from the body and its structure in motion, all sorts of obsessions-with anatomy, physics, the mind-began to surface! (Clarke, 2002, p. 9; emphasis in original)

Clarke's comment highlights the impact a change of perspective had on the quality of her practice. The shift of perception and thinking stimulated by the change of relationship with her body is the factor that stimulates ideas beyond dance. It is also the factor she identifies as developing her technique: 'when I began to learn more directly from my own proprioception I gained greater control, articulation, strength-those qualities we label as criteria of technique' (2002, p. 13). Clarke epitomizes the 'thinking dancer'; ${ }^{7}$ her practice reflects how the understanding of this concept is shifting to reflect the different conception of the body/mind connection exemplified in somatic practice. Duerden and Fisher venture that the term 'thinking dancer' is a tautology: 'dancing and thinking are not separate activities' (2002, p. 10). And subsumed within dancing — and thinking — may be sensing, feeling, reflecting, imagining, transcending.

In her research with dancers, Sara Reed observed that the value of somatic studies is in thinking differently, as this is important in teaching dancers to move differently (2002, p. 9). She quotes an experienced practitioner as stating, 'one needs to give them-the students-experiences where they are their own feedback' (Reed, 2002, p. 8). Educational psychologist Guy Claxton says that 'learning and awareness are two sides of the same coin' (1984, p. 188). Tully's concept helps the dancer shift thinking and awareness from an outside image of an ideal body to the inside sensory information of my ideal body in the dancing experience. I do not only look for feedback - in the mirror, at a teacher, at other ideal bodies. As soon as I release hold of the outside position/perspective on my dance, which is based in where and at what I look, I am released from the idea of an image as my feedback and can embrace what I feel and what I think conceptually. I can refer to the ballet vocabulary (e.g. glissade) not as an existing 'thing', but as a code that indicates many ideas-for example, quality of movement, gesture with a clear beginning and end, multiple variations in 
direction, speed, position in space, in relation to other dancers, in relation to other movements, particular organization of body parts and physical forces to coordinate the movement in space. There are performed examples of the glissade that I can refer to and assess on a number of levels. The word 'code' also suggests something hidden, something to solve, to discover ... something that requires my imagination, choices, me. As Susanne Langer (1983, p. 29; emphasis in original) says, 'only when a movement is imagined ... it becomes an artistic element, a possible dance-gesture'.

En dedans and en dehors can be imagined as loops on either side of a continuous stream of movement in the form of a figure-of-eight. If I walk hand in hand with others along the line of the figure-of-eight ${ }^{8}$ and focus on the feeling in my body, as I circle around one loop, I am aware of en dehors/opening in my body and closing/en dedans as I continue to circle around the other loop. My gaze is towards the outside of the circle on the en dehors loop and towards the inside of the en dedans loop. The idea of dehors/dedans and the feeling in my body suggest a way of conceptualizing my dance. I see the point of transition between en dehors and en dedans as the place where the inner and the outer world meet in the form of my dance. The geometry underpinning shape in ballet gives me a tool to relate imaginatively inwards to my inner physical space and outwards to the architecture of the space around me. Implicit in the movement inwards is its outward opposite, and vice versa. The movement I feel inwards and outwards connects with my breath, implying continuity with my body's rhythm, the heart and pulse, the conscious and unconscious. When I practise, my conscious inward breath opens my body and mind and on the outward breath my conscious body closes the form of the dance. If I lose my conscious self in dancing, if self and body/mind are indivisible, it is the dance which is dancing me. I am dancing.

Theorizing the experience of acquiring mind and bodily consciousness in learning to dance is complex. According to the conscious competence learning model matrix, ${ }^{9} \mathrm{a}$ practitioner moves through the following stages in the development of skill towards expertise: unconsciousness and incompetence, consciousness and incompetence, consciousness and competence and unconsciousness and competence. By this measure, if I am dancing, I am expert. I am practising at an expert level.

\section{Balancing the bodies of the dance}

Dancers and musicians share a notion of practice, as work to master the ability to play the instrument and, in dance, to construct the body as instrument. Engaging in disciplined practice does not mean becoming 'rule-bound', but enables mastery of the instrument and the freedom to play. For the dancer there is no escaping the materiality of her human body. For Wood (2002) performing or 'playing' is integral to the process of developing one's dance, and Clarke identifies 'each dancer's self, mind and body [as] the medium for learning and expression' (2002, p. 9). The sense of belonging to a community of practice and relationship to a body of dance knowledge are also part of what forges the individual dancer's identity: 'Understanding the interrelation between the "subjective content (that is of our sentient selves) ...[and] objective structure (discernible form)" is what reveals the metaphysical to the dancer in her purposeful undertakings' (Fraleigh, 1987, p. 161). Fortin suggests that the 'most 
interesting thing' about the imaginary boundary across the field of experience that defines what is inside or outside the self, is 'that it frequently shifts and even sometimes disappears' (2003, p. 4). Dissolving the boundaries between the dancer and the dance is one of the goals of expert performance, and mastery in practice is sometimes described as 'losing oneself' in the activity. This does not imply absence or deny the agency of the dancer and herself in the dynamic interrelationship of components that manifest as dance-body of dance knowledge, the dancer herself, her body for seeing the dance in time and space-but balance and poise at each moment of becoming. And when the whole is perceived as greater than the sum of its parts, a transformation from the material occurs. Form embodies ideas on a poetic level. The dancer transcends her body to become her dance.

Leslie Edwards's career with the Royal Ballet spanned 60 years and several generations of dancers (1933-93). In conversation about the Royal Ballet Choreographic Group, in 1994, ${ }^{10}$ that he had initiated, he suggested that a problem had arisen in referring to dance-not dancing. I think that Edwards, in his wisdom, saw that the language used would influence how dance is practised and how it is perceived in performance. Naming the activity of dancing as dance shifted the emphasis towards shape not movement, body image not quality of dancing, fixed form not fluid practice. In dancing, movement forms shape and shape sustains movement-balance hovers between them:

At the still point of the turning world. Neither flesh nor fleshless

Neither from nor towards; at the still point, there the dance is

But neither arrest nor movement.

(T. S. Eliot, 'Burnt Norton', Four Quartets, 1935-42)

\section{Conclusion}

Working with en dehors/en dedans as a concept allows me to draw somatics and ballet practice together to examine the relationship of the individual dancer with the discipline, her instrument and her dance and the integration of body, mind and self in dancing. For me ballet is both a somatic practice and a particular form of dancing that delights my body/mind, promotes my health and gives me a framework to develop as a human being and an artist. Adopting the first-person perspective, I see practice in a categorically different way from those who view bodies. My experience of dancing is of movement, and the form, which is always evolving, is the means of communicating my dance. It is the 'presence of an audience [that] gives dance its artistic discipline' (Langer, 1983, p. 42). I have touched on strategies for practice implied by the conjunction of just one aspect of ballet principle and Tully's idea of the ideal body. Much is unexplored-in particular, the role of the emotion, feeling and creativity in practice.

Foster and Copeland provoke much needed debate about ballet. As expert spectators their mastery is in the writing (in the manner elucidated by Melrose, 2003) and positioned outside of practice. I am not arguing for dancing as against dance, but for more rigorous scrutiny inside and outside practice in the use of language and 
the given texts. Copeland commented that his 'growing dissatisfaction with a criticism intensely focused on description' reflected what he perceived as a bias against ideas in dance (1993, p. 26). As a ballet practitioner searching for reasons behind my continued dissatisfaction with dance that appears to be focused on reproduction of a prescribed notion of an ideal and athletic body, I could come to a similarly depressing conclusion. Does one kind of body reflect a lack of ideas in the ballet? What is the impact of the narrowing of focus to one particular kind of body on the ability of the art form to present and provoke a range of ideas about ballet as art? On how many levels can an audience connect with a performance where the bright body as instrument blinds us from seeing the dancer within? How can we see the wider world of ideas mirrored in the body? And connect with dance as shared human experience?

The role and influence that dance education has on the development of dancers as people and artists is highlighted by practitioners such as Seymour. Dance is used instrumentally within mainstream education to promote skills other than the physical-for instance, social, communicative, creative and analytic. Dance demonstrates that it can reveal the world outside. In her book on the role of the emotions in vocational education of the student dancer, Julia Buckroyd (2000) argues that ballet can be positive in the development of the individual self. A shift of emphasis is required, from the body as object, towards the human being who engages the dance as subject and as art-i.e. balance.

If we do not have the courage to be ourselves, to speak and dance from our own experience, we as practitioners are complicit in surrendering authority to the outside of our practice, to the fixed text (dance or written) and all that that may imply in terms of arrested creativity in practice. By chance a dancer has the prescribed ideal body. To become an artist implies a quality of practice:

True ease in writing comes from art, not chance,

As those move easiest who have learn'd to dance.

(Alexander Pope, An essay on criticism, 1711)

\section{Notes}

1. Ballet Independents' Group (BIG) Discussion Forum, in June 2002, highlighted different perspectives: practical, philosophical and academic on 'Ballet - vocational and academic study'. I have drawn on speakers' comments and the discussion from the floor; speakers were Chris Challis (education philosopher), Michael Irwin (Professor of English, Kent University) and Patrick Wood (practical ballet teacher). A transcript of the discussion is available for researchers at: National Resource Centre for Dance (NRCD), University of Surrey, Guildford, UK, and reported in Jackson (2002).

2. Exploring the concept of en dehors more broadly, it serves as a good metaphor for a correlation between openness of the body and mind. I identify strongly with the ideas of neuroscientist Antonio Damasio regarding the symbiotic relationship of the body/brain in the process of optimal functioning. In Looking for Spinoza: joy, sorrow and the feeling brain (2003), he says: 'In the same way that the brain reacts to a problem in the body, it also reacts to the good function of that body. When the body operates smoothly, without hitch and with ease of transformation 
the body frame' (2003, p. 33).

3. This paper discusses only one of many ideas that are raised in the context of Tully's class. He gave me this form of words for the idea in July 2004. He invites and uses questions as part of the learning development of both teacher and student; intellectual enquiry is embedded in practice. I am grateful to him and my colleagues Patrick Wood, Susan Crow and Noni JenkynJones for numerous discussions and the practical exploration that have helped to develop my thinking.

4. At the time of writing, Anna Paskevska's book Ballet beyond tradition:the role of movement concepts in ballet technique (2005) has been published. She discusses the application of movement concepts from modern dance technique (Limon) in teaching ballet. Many of the ideas, in particular, the potential of exploring relationships between different technique studies and the experience of dance from the inside, resonate with those that I investigate in this paper.

5. Barbara Fewster was Ballet Principal of the Royal Ballet School (1968-88) and Peter Wright was Artistic Director of Sadlers Wells Royal Ballet and Birmingham Royal Ballet (1977-99).

6. Ballet Independents' Group Discussion Forum, May 2001, debated the topic 'Ballet-bodyimage' in the wake of the publicity surrounding Keefer's complaint and the death of Heidi Gunther and subsequent court case against Boston Ballet brought by her mother.

7. Michael Huxley links the idea of the thinking dancer who emerges from higher education as the 'person' who demonstrates a 'rigorous and open spirit of enquiry' (2002, p. 12).

8. Patrick Wood introduced me to the idea of walking in a figure-of-eight as a way of revealing the feeling of en dehors and en dedans in the body.

9. Source: Alan Chapman (2001-4); available at: http://www.businessballs.com

10. Interview with Leslie Edwards, in 1994, for a study on performances by Royal Ballet Choreographic Group, in 1981, at Riverside Studios, London.

\section{References}

Adshead-Lansdale, J. (1981) The study of dance (London, Dance Books).

Alexander, K. (2003) Unravelling the dance: an exploration of dance's under-developed relationship with its kinaesthetic nature, with particular reference to Skinner releasing technique, in: New connectivity: somatic and creative practices in dance education. Papers from Laban Research Conference (London, Laban Centre for Movement and Dance), 19-22.

Buckroyd, J. (2000) The student dancer (London, Dance Books).

Challis, C. (2002) Ballet-vocational and academic. Ballet Independents' Group Discussion Forum (transcript), University of Surrey, NRCD.

Clarke, G. (2002) Making space for the tortoise-educating creative individual artists! in: Finding the balance. Dance in Further and Higher Education in the 21st Century Conference Proceedings (CD-ROM) (Liverpool, Liverpool John Moores University, Dance Department).

Claxton, G. (1984) Live and learn: an introduction to the psychology of growth and change in everyday life (Milton Keynes and Philadelphia, PA, Open University Press). 
Cohen, S. J. (1982) Next week, Swan Lake: reflections on dance and dances(Middleton, CT, Wesleyan University Press).

Copeland, R. (1986) The objective temperament, Dance TheatreJournal, 4(2), 6-11.

Copeland, R. (1993) Roger dance criticism and the descriptive bias, Dance Theatre Journal, 10(3), $26-31$.

Crow, S. \& Jackson, J. (1999) Balancing the books, Dance Theatre Journal, 15(1), 36-40.

Crow, S. \& Jackson, J. (2001a) The legacy of de Valois, Dance Theatre Journal, 17(3), 12-16.

Crow, S. \& Jackson, J. (2001b) Ballet-body_image, Ballet Independents' Group Discussion Forum flier, University of Surrey, NRCD.

Damasio, A. (2003) Looking for Spinoza: joy, sorrow and the feeling brain (London, Heinemann).

Duerden, R. \& Fisher, N. (2002) Thinking dancers: finding a balance in the training of undergraduate dancers (or, the relevance of technique for the student dancer), in: Finding the balance. Dance in Further and Higher Education in the 21st Century Conference Proceedings (CD-ROM) (Liverpool, Liverpool John Moores University, Dance Department).

Fortin, S. (2003) Dancing on the Möbius band, in: New connectivity: somatic and creative practices in dance education. Papers from Laban Research Conference (London, Laban Centre for Movement and Dance), 3-10.

Fortin, S., Long, W. \& Lord, M. (2002) Three voices: researching how somatic education informs contemporary dance technique classes, Research in Dance Education, 3(2), December, 155-275.

Foster, S. L. (1995) Harder, faster, longer, higher-a postmortem inquiry into the ballerina's making, in: Border tensions, dance and discourse: Proceedings of the Fifth Study of Dance Conference (Guildford, University of Surrey), 109-114.

Foster, S. L. (2003) Dancing bodies, in: J. C. Desmond (Ed.) Meaning in motion (Durham, NC, and London, Duke University Press), 235-257; original work published 1997.

Fraleigh, S. H. (1987) Dance and the lived body (Pittsburgh, PA, University of Pittsburgh Press).

Geeves, T. (1993) Training or taming the dancer? in: Tomorrow's dancers. Papers of the 1993 Conference 'Training Tomorrow's Professional Dancers' (Dance UK) (London, Laban Centre for Movement and Dance), 8-19.

Geeves, T. (1994) The difference between training and taming the dancer, in: The Art of Teaching Dance Conference papers (Brisbane, Australia Dance Council), 4-23.

Hanna, T. (1995) What is somatics? in: D. H. Johnson (Ed.) Bone, breath, gesture: practices of embodiment (Berkeley, CA, North Atlantic Books), 341-352.

Hawkins, M. (1999) Training for the profession, Ballet Independents' Group Discussion Forum (notes), University of Surrey, NRCD.

Huxley, M. (2002) The thinking dancer, in: Finding the balance. Dance in Further and Higher Education in the 21st Century Conference Proceedings (CD-ROM) (Liverpool, Liverpool John Moores University, Dance Department).

Irwin, M. (2002) Ballet-vocational and academic, Ballet Independents' Group Discussion Forum (transcript), University of Surrey, NRCD.

Jackson, J. (2002) Curious frontier, ballet: vocational and academic study (Ballet magazine). Available online at: http://ballet.co.uk/magazines/yr-02/sep/02/jj-curious-frontier.htm (accessed 29 September 2002).

Kirstein, L. (1983) The aria of the aerial, in: R. Copeland \& M. Cohen (Eds) What is dance? (Oxford, Oxford University Press), 238-243.

Knorr-Cetina, K. (2001) Objectual relations, in: T. Schatzki, K. Knorr-Cetina \& E. Savigny (Eds) The practice turn in contemporary theory (London and New York, Routledge), 175-188.

Langer, S. K. (1983) From feeling and form: virtual powers, in: R. Copeland \& M. Cohen (Eds) What is dance? (Oxford, Oxford University Press), 36-47.

Lawson, J. (1960) Classical ballet: its style and technique (London, A. \& C. Black).

Melrose, S. (2003) Curiosity of writing (or, who cares about performance mastery?) Available online at: http://www.sfmelrose.u-net.com/curiosityofwriting/ (accessed 20 June 2004). 
Paskevska, A. (2005) Ballet beyond tradition: the role of movement concepts in ballet technique (New York and London, Routledge).

Polster, E. (1995) A population of selves (San Francisco, CA, Jossey-Bass).

Reed, S. (2002) A question of balance, somatic practices in dance education, in: Finding the balance. Dance in Further and Higher Education in the 21st Century Conference Proceedings (CD-ROM) (Liverpool, Liverpool John Moores University, Dance Department).

Rogers, C. (1977) The self: what it means to become a person (New York, Harper), 203.

Seymour, L. (2000) Ballet education: are we forgetting fundamentals? Dancing Times, January, 313.

Stokes, A. (1983) Tonight the ballet: the classic ballet, in: R. Copeland \& M. Cohen (Eds) What is dance? (Oxford, Oxford University Press), 244-255.

Wood, P. (2002) Ballet-vocational and academic, Ballet Independents' Group Discussion Forum (transcript), University of Surrey, NRCD. 